\title{
L2 Acquisition of Complement Clauses by Persian Learners of English
}

\author{
Masoud Khalili Sabet \\ Faculty of Humanities, University of Guilan, Iran \\ E-mail: sabetma2002@yahoo.com \\ Maryam Hadaeghi Azad (Corresponding author) \\ Pardis Branch of University of Guilan, Rasht, Iran \\ E-mail: maryamhadaeghi@yahoo.com \\ Amir Mahdavi Zafarghandi \\ Pardis Branch of University of Guilan, Rasht, Iran \\ E-mail: mahdavi1339@gmail.com
}

Received: 15-07-2014

doi:10.7575/aiac.ijalel.v.4n.1p.26
Accepted: 19-08-2014

Published: 01-01-2015

URL: http://dx.doi.org/10.7575/aiac.ijalel.v.4n.1p.26

\begin{abstract}
This research concentrates on the acquisition of complement clauses within Universal Grammar framework which theoretically plays the strongest linguistic role in second language acquisition research in recent years. This study aims to investigate how Persian learners of English at three levels of proficiency acquire complement clauses. In fact, this study reports the results of the learners' responses to GJT and specifically investigates the six linguistic variables associated with complement Clauses: using complement in finite/ non-finite clauses, small-clauses, exceptional-clauses, that-trace effect in clauses and subcategorization of two verbs (i. e. want and let). The responses were given by 50 Persian learners of English divided into three proficiency levels: Elementary, Intermediate and Advanced. The statistical analyses of the data revealed that, by increasing the participants' level of proficiency their judgment of grammatical and ungrammatical items was improved whereas the differences between groups were also significant. The results can indicate that the development of their complement acquisition is generally systematic. In addition, by carrying out syntactic analyses of the sentences that the participants produced, we conclude that, as UG predicted, Persian learners do not use any wild grammar at any level of their L2 acquisition. The above findings are generally in harmony with the view that L2 learners somehow attain the unconscious knowledge that goes beyond what they receive as L2 input. Finally, our findings may have implications for language teaching by deepening our understanding of the nature of $\mathrm{L} 2$ acquisition.
\end{abstract}

Keywords: Second Language Acquisition, Complements, Clauses, Developmental stages, Systematicity, Universal Grammar, Fundamental Different Hypothesis (FDH)

\section{Introduction}

Second Language Acquisition (SLA) can be defined as "the way in which people learn a language other than their mother tongue, inside or outside of a classroom" (Ellis, 2003, p. 3). L2 learners bring an enormous amount of knowledge to the task of learning a second language. They have already learned a language (their mother tongue) which they are expected to transfer in the process of L2 learning. They also possess general knowledge about the world which they can draw on to help them understand L2 input as well as communication strategies that can help them make effective use of their L2 knowledge.

This research concentrates on L2 learning of complement clauses within Universal Grammar inspired by contemporary linguistic theory because it has had the strongest linguistic influence on second language acquisition research in recent years, and has inspired a great wealth of studies, articles and books on SLA both empirical and theoretical. While the majority of linguists have no doubt about the presence of UG in L1 Acquisition, its availability in L2 Acquisition in general, and particularly in adult L2 acquisition, is controversial (e.g. Bley-Vroman, 1989, 2009; Clahsen, 1995). The idea that adult L2 acquisition might be similar in nature to L1 development and whether there is access to UG in L2 acquisition like L1 acquisition have been controversial in the last decades. There have been proponents (e.g. White, 1998, 2003) for access to UG in L2 acquisition and opponents (e.g. Clahsen \& Musken,1986; Clahsen 1995) who believe that "UG is dead" in adult L2 acquisition. On the other hand, a number of researches (Dulay et.al., 1982; Cook, 1997) believe that L2 learners systematically pass through developmental stages similar to children in acquiring their L1. However, some researchers (Mitchell \& Myless, 2013) believe that L2 development is partly systematic. In addition, the concept of Interlanguage (IL) introduced by Selinker $(1969,1972)$ is not an incomplete or deviant form of 
the TL that can be simply compared and judged based on the Target norms, because L2 learners creatively construct an IL system and develops it in its own internally logical and valid mechanism. As Cook (1997) argued, although, IL system may, at each stage be very different from the TL, and constantly changing, they are systematic.

This study has investigated how Persian learners of English as second language learners, at different levels of proficiency acquire complement clauses, whether their language development is systematic in the sense that they use any wild grammar at any of the levels of proficiency (i.e. using grammar in their Interlanguage that violates the UG principles). One way of doing this is by collecting samples of learning language - language which L2 learners produce when they are called on to use an L2 in speech or writing- and analyze them carefully. These samples provide evidence of what learners know about language and what they are trying to learn about target language.

The area selected to test these questions is that-complement clauses because, clauses are the main unit of syntax and " head-complement is the core locate relation" (Chomsky 1992, p. 9), on the other hand, there are some interesting differences between Persian and English in the realization of that-complement clauses. According to Kidd, Lieven \& Tomasello (2010, p.1), "Complement clauses are sentential structure that functions as an argument of a matrix verb". The complement clause can occupy the subject argument slot, as in (1), or the object slot, as in (2) (the complement clause is underlined).

(1) That Jane was late angered his mother.

(2) Jane could see that he had angered his mother.

In the unmarked case (2) the complementiser that is optional, and consequently the complementiser does not occur frequently in the naturalistic speech of children or adults in English language (Diessel \& Tomasello, 2001; Thompson \& Mulac, 1991). A number of syntactically distinct complement clauses can be identified. However, this study will examine the following six main areas: Finite/Non-finite, Exceptional Clauses, Small Clauses, That-trace filter and Subcategorization of two verbs (want, Let) that we will explain about them in short.

\subsection{Finite and Non-finite Clauses}

Finite and non-finite clauses have been differentiated by Radford (1997) as follows:

The distinction between finite and nonfinite Clauses is based partly (though not wholly) on morphological criteria: thus, a Clause is finite if it contains a finite verb (a verb inflected for Tense/Agreement), and nonfinite if it lacks a finite verb (Radford, 1997).

In (3) the complement clause is finite, since the subordinate verb contains tense and agreement, whereas, in sentence (4) the complement clause lacking tense and agreement is nonfinite and the subordinate verb is tense less.

(3) I see Mary walked to the Institute this morning.

(4) Mike enjoys chatting with his students

\subsection{Exceptional Clauses and Small Clauses}

A number of linguists have suggested that there are two unusual types of complement clause which don't have S-bar status referred to as Exceptional Clauses (EC) and Small Clauses (SC) (Radford, 1997, p. 317). ECs occur as the complement of a subset of verbs (especially 'cognitive verbs', i. e. verbs of saying or thinking):

e. g.: (i) I believe [the president to be right]

Such ECs are typically of the form [NP to VP]. According to Radford (1997, pp. 317-318) these clauses are 'Exceptional' as they cannot be represented by an overt Complementizer such as for:

e. g.: (iii)* I believe [for the President to be right]

Because firstly, Complements are constituents of S-bar and $\mathrm{S}$ Constituents cannot in principle contain Complementizers.

$$
\begin{array}{lll}
\mathrm{S} \longrightarrow \mathrm{NP} & \mathrm{M} & \mathrm{VP} \\
\mathrm{S} \longrightarrow \mathrm{C} & \mathrm{S} &
\end{array}
$$

Secondly, in ECs their subjects behave like objects of the preceding verb rather than the subjects of the following verb.

e. $g$ (1). I consider [the patient to be in great pain]

Thirdly they can undergo passivisation like the object of typical verb.

e.g. (2): They are considered [ _ to be conscientious]

In addition, they can surface as a Reflexive whose antecedent is the main clause subject. 
e. g. (3): My students consider [themselves to be conscientious]

"If EC are S complements, then we can say that passivisation etc. can apply across S, but not across S-bar" (Radford, 1997, p. 318).

There is another kind of clause called 'Small Clause' (SC) which is an important part of syntactic theory and does not have verbal predicates (that is, a DP, PP, or AP serves as the predicate). These generally do not get tense marking. An example is the embedded string in:

\section{e. g.: I believe [the President incapable of deception]}

So, SC are simple Subject+ Predicate Structure of the schematic form [NP XP], and SC lack a C constituent, and hence cannot have S-bar status and they cannot be introduced by overt complementisers. Since Small Clauses are smaller than Ordinary Clauses, and lacking both $C$ and $I$ They are named as Small Clauses.

To sum up, Ordinary Clauses are $S$-bar constituents of the form [C NP I VP]; Exceptional Clauses lack $C$ altogether and are simple $S$ constituents of canonical form [ NP I VP], and Small Clauses which lack both $C$ and $I$ have the canonical structure [NP XP], in which XP = AP, NP, PP, etc. (Radford,1997, p. 331).

\subsection{The Projection Principle}

The Projection Principle is a stipulation or rule which is as part of the Phrase Structure Component of GenerativeTransformational Grammar ( Chomsky, 1986). Under the Projection Principle, the properties of lexical items must be preserved while generating the phrase structure of a sentence. The Principle, as formulated by Chomsky (1986) states that "lexical structure must be represented categorically at every syntactic level" (p. 84). Chomsky further defined the projection principle as representations at each level of syntax (MF, D, S) projected from the lexicon in that they observe the Subcategorisation properties of lexical items. In fact, "the theory integrates the syntactic description of sentence with the properties of lexical items via the projection principle, which require the syntax to accommodate the characteristic of each lexical item" (Cook, 1997, p. 17). There is always restriction on words which can occur in a construction. The linguistic description expresses this through the lexical entry that each item has in the lexicon (ibid). For example, some verbs such as want are followed by an NP (an object NP) or by a phrase starting with to: 'I want an ice cream.'; 'I want to leave.', but it may not be followed by a phrase starting with that. E. g.: '*I want that Bill leaves.' This is known as subcategorization frame. However, some verbs such as believe may be followed by NP or that phrase. e. g.: 'I believe that Bill left'.

The entry for 'want' is something like: want Verb, [_ NP/ to-phrase]; and the entry for believe: believe Verb, [ $\mathrm{NP} /$ that-phrase]. But in Persian language the verb 'khastan' (i.e. want), and 'eteghad dashtan' (i. e. believe) can be followed by the complementizer ' $K e$ ' (that) i. e. either verbs can be followed by a phrase starting with that (Ke). This is true for the verb like 'let' too. In contrast to English language, let in Persian can be followed by that phrase.

e. g.: P: Man ejaze dadam ke ou beravad.

E: I let him go.

In Persian, that-complement clause is characterized by complemntizer ' $K e$ ' that is specific to Persian and there is no other way to state such clauses.

e. g. (11) (P): Man midanam ke to dar an emtehan mardood shodi.

(12) (T): I know that you on exam failed.

(13) (E): I know that you failed on the exam.

In English, however, there are various constructs parallel to complementizer Ke in Persian such as that, whether, if in finite and whether, for in nonfinite clauses. Since increasing awareness of language and its construction and that how learners do develop their interlanguage may have many educational advantages and indeed help L2 learning in a broad sense, this study investigates acquisition of complement clauses by Persian learners at different levels of proficiencies.

\subsection{That-trace Filter}

Finally, in non-pro-drop systems sentences such as '* Who did Ali say that bought the car?' are considered ungrammatical while its corresponding structure as 'Who did Ali say bought the car?' is argued to be well-formed. It is; therefore, legitimate to generalize that in non-pro languages such as English the subject of the subordinate clause may be questioned just if the complementizer 'that' is absent. The main argument is that the first type of sentences in English are ungrammatical because they violate a principle of grammar termed as 'Empty Category Principle' by movement from the subject position if the complementizer is present (Radford, 1998), while the first type of sentences in Persian would be permitted because movement is possible from post-verbal position in the inverted sentence form.

\section{Theoretical Research Background}

In the theory of Universal Grammar, principles and parameters are supposed to constitute the innate cognitive faculty that makes it possible for human being to acquire language. That is to say that we are born with a set of rules about language in our head, which Chomsky (1950) refers to as Universal Grammar. The UG is the basis upon which all 
human language builds. In other words, "this universal set of principles and parameters control the shape human language can take, which make human languages similar to one another" (Mitchell \& Myles, 1998, p. 43). A controversial question will be, whether the same principles are accessible to second language learners. A number of L2 researches propose that there are differences between L1 acquisition and L2 acquisition for some reasons (Schachter, 1989, 1996; and Bley-Vroman, 1989,1990, 2009; Clahsen \& Felser, 2006). They believe that second language acquisition do not function as first language acquisition for following reason: first, few SLA learners can gain a knowledge of L2 equivalent to that of the L1, unlike first language acquisition in which children acquire full L1s (Selinker, 1972; Schachter, 1996; Johnson \& Newport, 1989; Cook, 1997). Secondly, children progress from an initial state to a final state of knowing everything about a particular language. L2 learners, however, already have the knowledge of L1 (White, 1992, 2003). Thirdly, second language learners are occasionally exposed to different types of negative feedback (Mitchell, Myles, \& Marsden, 2013). Finally, the achievement of second language learners are influenced by variables such as age, motivation, attitudes, personality factors (Towell \& Howkins, 1994), etc. However, some researchers claim that successful second language learners usually attain very unconscious knowledge of the target language, while the linguistic input from L2 is insufficient (i.e. the input underdetermines their L2 linguistic competence) (White, 1985, 2003; Cook, 1988,1997). However, there is still little doubt that the UG approach to research into second language acquisition has been highly influential and fruitful. On the one hand, it has been very useful as a sophisticated tool for linguistic analysis, enabling researchers to formulate well-defined and focused hypotheses which could be tested in empirical work. Therefore, UG would be a powerful linguistic tool which is useful in describing not only the language produced by learners, but also the language to be acquired as well as the first language of the learner. On the other hand, this approach also met some success in explaining the fact about second language acquisition. For example, it has informed our understanding of the stages L2 learners go through, and of the systematicity of the L2 learners' language development. If learners are constrained by UG, we would expect their development to be staged and systematic, similar to children's L1 development. UG also enables L2 researchers to draw up a principled view of language transfer/ cross- linguistic influence, in terms of principles and parameters which enable us to test empirically whether parameters can be reset (Mitchell \& Myles, 1998).

\subsection{Universal Grammar and Second Language Acquisition}

UG is a system of principles and parameters which provides constraints on grammar in L1 acquisition as well as adult native speaker grammars developments. L2 learners as well as L1 learners need to arrive at a linguistic system allowing them to understand and speak the second language. The heart of UG model of acquisition is the argument that since "people know aspects of language that they could not have learnt from the speech they have heard, this must already be built in to the human mind, that is, be innate" (Cook, 1993, p. 207). This is known as the Poverty-of- the stimulus argument, or 'Plato's problem'. UG is a general theory of language, which should therefore apply to learner language, alongside other language varieties. In practice, one of the main interest of the UG approach for SLA research is that "it provides a detailed descriptive framework which enables researchers to formulate well-defined hypotheses about the task facing the learner, and to analyze learner language in a more focused manner" (Mitchell, Myles, \& Mardsen, 2013, p. 63). Therefore, by comparing what goes into UG and what L2 learners produce, we can find out what is in the middle (the knowledge of language that is necessarily part of the human language faculty). The question whether UG also mediate L2 acquisition, and to what extend has been investigated and debated since 1980s. The first decade of research on UG in L2 acquisition concentrated on the access issue (i.e. access to UG in L2 acquisition) (White, 2003). A number of researches looked for evidence that learner can (or cannot) apply principles of UG set or reset parameters as well as investigating the extent to which the L1 is involved in L2 acquisition. Three hypotheses have been offered whit respect to the role of UG in adult L2 acquisition: no access, direct access, indirect access and no access to UG.

\subsubsection{Direct access to UG}

In this hypothesis L2 learner have access to UG i. e. inter-language grammar show evidence of being constrained by UG principles and evidence of parameter setting other than those of the L1. Flynn (1996) adopts this position arguing that UG continues to underpin L2 learning for adults as well as children, and that there are no such things as a 'critical period' after which UG stops to operate. Then, L2 learner may employ the principles of UG and set parameters without any reference to L1 values. Therefore, "L2 learners have the same access to UG as L1 children" (Cook, 1997, p. 292). Otsu \& Naoi' (1986 cited in White, 1989) also suggest that L2 learners have direct access to UG.

\subsubsection{Indirect access to UG}

In indirect access, L2 knowledge is tied into L1 knowledge. L2 learners are indeed assumed to have access to principles and parameters of UG, but this access would be via L1 grammar, whit the possibility of subsequent grammar restructuring and parameter resetting in the light of exposure to L2 input. Therefore, if L2 possesses parameter-setting different from those in L1, L2 learners will have to reset the parameters though other mechanisms in order to make the L2 data fit their internal representations. These mechanisms will be rooted in general problem- solving strategies.

\subsubsection{No-access Hypothesis}

Proponents of this view argue that child L1 and adult L2 acquisition differ in major respect and adult L2 acquisition is not constrained by UG or that is only constrained by UG as universal properties can be accessed via the L1 grammar. "The crucial clam is that all the linguistic mechanisms available to L1 acquirer are not available to the L2 learner" (White, 2003, p. 16). The proponents of this hypothesis tried to show that learners are 'stuck' with principles and 
parameters setting in their L1 (e. g. Schachter, 1989) or that their grammar show no evidence for UG at all (e.g. Clahsen \& Muysken, 1986). Bley-Vorman (1989) has also argued that if there is inefficiency to L2 learning, it is because L2 learners do not have UG available to them. They acquire L2 through other mental processes. In other words, they resort to general learning strategies.

\subsection{The logical problem of language acquisition}

The logical problem of language acquisition refer to the way the learners fully develop the grammatical system of the language in spite of their limited exposure to the language input around them (White, 1989, pp. 4-5; 2003). Although UG contributes to an explanation of how language are acquired, this is in the sense of how learners come to know properties that go far beyond the input, how they know that certain things are not possible, and why grammars are of one sort rather than another, etc. (White, 2003). Therefore, the claim is that these properties don't have to be learned. The claims for an innate UG are motivated by the fact that in L1 acquisition there is a mismatch between the input or primary linguistic data (PLD) or utterances which a child is exposed to and the abstract, subtle, and complex knowledge, the child acquire. In other words, the input underdetermines the output. This is known as the problem of the poverty of stimulus or the logical problem of language acquisition (ibid, p. 20). By this assumption of logical problem in L1 acquisition in which it is logically impossible for the child to learn structure of human languages (which are so complex and abstract) only on the basis of evidence from the input to which $\mathrm{s} / \mathrm{he}$ is exposed, people have asked whether the same hold true of L2 (White, 1998; Bley-Vroman, 1990).

\subsubsection{Fundamental Difference Hypothesis (FDH)}

Bley-Vroman $(1989,2009)$ Fundamental Difference Hypothesis (FDH) posits that the acquisition process of children and adults is fundamentally different from another because children possess the innate ability to acquire the L1 grammar, whereas adults have lost this ability and thus need to utilize problem solving skills and conscious attention to acquire L2. The FDH argues "cognitive abilities are drawn on in adult SLA", in contrast to L1 acquisition, which "develops under the constraints of UG" (Robinson, 2002, p. 116). The "fundamental difference" between child and adult language acquisition, then, is that children acquire language by first passively recognizing the parametric values particular to the target language grammar, then setting the parameters accordingly in their internal grammatical representations (a domain-specific mechanism). Adults rely instead on general problem solving skills to consciously construe the grammatical structure of the L2 input. Since individuals vary in their ability to employ these skills, the FDH explains why the outcome of adult language acquisition is both less morphosyntactically native-like and less uniform across individuals than that of child language acquisition.

Epstein, Flynn and Martorjardjono (EFM) (1996) maintain that Clahsen and Muysken (1986), Clahsen (1998) and BleyVroman (1989) offer the most radical formulations of the FDH by stating that L2 acquisition is governed by cognitive faculties that are separated and distinct from the domain-specific language faculty: UG. "Postulating that UG constraints L2 knowledge growth does not entail identical development trajectories for L2 and first Language acquisition, nor it precludes a role for the L1" (EFM, 1996, p. 746). This quote clearly shows that, Epstein, Flynn and Martohardjono don't exclude the L1's role an L1 as initial state or an L1 filtering all input data. However, BleyVroman (1990) in the specific proposal stated that adult L2 learners do not have access to UG and that for these learners the initial state (initial representation) is the L1. However, recent research has shown that Critical Period Hypothesis $(\mathrm{CPH})$ cannot be maintained as originally suggested, because maturational change happen at a much earlier age than suggested by Lenneberg (1967) and this is against Bley-Vroman (1990, p. 30) assumption that LAD should still be accessible in the late teens (Meisel, 2011, p. 195). In other words, since adults are clearly capable of learning a second language after puberty, it is impossible to argue for a monolithic (i.e. unchangeable) critical period in adult L2 learning. Moreover, traditional wisdom on critical periods which means there is a hard and fast limit on the accessibility of UG to adult learners is less than convincing (Eubank, 1991,p.35-36). However, it may be the case that some aspects of language learning have a critical period (e. g. pronunciation).

\subsection{Systematicity and variability in SLL}

For a teacher examination and comparison of an SLL utterance with traditionally accepted TL norms, often errors have been viewed as learners' carelessness or their lack of concentration. So, if they would practice more, their productions could be like the TL and surely reflect its rules. One of the big lessons that has been learnt from the researches of recent decades is that "though learners' second language utterances may be deviant by comparison with target language, they are by no means lacking in system" (Mitchell and Myles, 2013, p. 15). Mitchell and Myles believe that errors and mistakes are patterned and although some regular errors are caused by the influence of the first language, this is by no means true of all of them. They believe that "there is a good deal of evidence that learners work their way through a number of developmental stages, from apparently primitive and deviant versions of the second language, to progressively more elaborate and Target-like versions" (ibid, p. 16). In other words, second language learners' utterances can be described by a set of underlying and interim rules which have their own integrity rather than just to be inadequately applied versions of the TL rules.

The data which has been studied for a range of TLs has commonly been interpreted to show that, at least as far as key parts of the second language grammar are concerned, learners' development follow a common route, even if the speed (or rate) at which learners actually travel along this common route may be very different. In early stage this systematicity in the SLL production is paralleled with that through which first language learners would pass in a highly 
regular manner. However, intrlanguage is not, only characterized by systematicity, but rather -indeed, is hopefullyunstable and in the course of change. It is also characterized by high degrees of variability (Towell and Hawkins, 1994, p. 5). Since learners' utterances seems to vary in the types of errors they have made, from moment to moment, they seems liable to switch between a range of correct and incorrect forms over lengthy periods of time. This variability in interlanguage (in SLL) is more extreme than that found for children in their first language (Mitchell and Myles, 2013, p. 16).

According to Mitchell and Myles (2013) "learners' interlanguage production can be described as systematic, at least in part" (p.17). In fact, learners' surface utterances can be linked to underlying rule system even if these seem primitive and deviant compared with TL system and the rule system of these utterances which learners produce can generate utterances that are appropriate to a given context which the learner has never heard before.

As Sharwood smith $(1994$, p.31) pointed out "there are two kinds of creativity to be found in the language learner's achievement: developmental creativity and structural creativity." Developmental creativity means the forming of original rules that may actually defy the evidence of language encountered by the learner. Structural creativity means that the learners can produce entirely original systematic utterances whether or not they are native-like. He also believes that there is a great deal of evidence in first language acquisition as well as second language acquisition in which learners 'go their own way' and create novel forms which are representations of some personal grammar of the language.

\subsection{Systematicity and the representation of overtime Interlanguage development}

In order to account for systematicity in interlanguage, different explanations have been offered in research on second language acquisition. Recent accounts have confronted us with explanations that attempt to give details on interlanguage development. The main reason for disagreement among researchers seems to be the discreteness or the lack of specific characteristic aspect in the portrait of interlanguage development at different points in time. The antagonism of these theoretical stances has resulted in representations that differ across frameworks for the study of interlanguage systematicity. Some representations view interlanguage development as a linear, discrete, stepwise and non-gradual process. This is the view that informs research on 'stages' of acquisition and on information processing. The core theoretical thought of this research is that development takes place in passing through a series of discrete stages. As a consequence, the transition from one stage to the next is a 'stepwise movement' from one set of grammatical rules to another. In other words, a linguistic form or structure that is not part of a learner's interlanguage at a given stage or point in time is present in subsequent stages ( Sanchez Perez ,2010). Sharwood Smith and Truscott (2005) claim "there are periods of relative stability followed by shorter periods of transition within which structural changes take place" (p. 222).

Another assumption is that interlanguage development is non-linear, non-discrete and gradual ( Dulay and Burt, 1977). That is, this representation sees development as a matter of gradual growth along a continuum. This framework, has criticized the sequencing of interlanguage development into stages over time. The major criticism is that division interlanguage development into stages leaves no room for variation and presupposes an abrupt transition between stages.

A second major criticism is the determination of categorical criterion in the establishment of developmental stages. In other words, in this view, interlanguage development takes place not as a 'stepwise' movement or as a sudden abandonment of one set of rules in favor of another one, but as a gradual growth in frequency of use of each structural solution. The term 'stage' has been used to refer to the order in which linguistic structures are mastered, rather than to the order in which they will be appear in the learner's interlanguage.

The MOGUL was developed in Sharwood Smith (2004) and Truscott and Sharwood Smith (2004) as an intermediate solution that makes an effort to integrate movement from one structural solution to another and co-existence of different solutions into a single whole is proposed within the MOGUL framework. It is in this latter work where they point at the fact that 'grammatical development can be seen in both ways, as stage-by-stage and gradual' (p. 211), and use this reasoning to reconcile 'stages' and 'continua'.

\subsection{Development in second language acquisition}

The notion of second language acquisition as implying that learners' knowledge of the target language changes over time from the initial toward the final state, draws attention to the idea of linguistic development. Second language research up to late sixties of the twenties century focused primarily on the end result and the ability to use the L2 rather than on the process of acquisition or the cognitive capacity underlying it. In the early 1960s L1 research started to entertain the idea of LAD which not only defines the initial state of L1 development (the implicit knowledge), but also determines the course of development since it require that children's grammar conform to principles of UG. The question of whether LAD also guides L2 acquisition was not addressed in a systematic fashion until the late 1960s (Robinson, 2013). Corder (1967) was the first one who suggested that L1 and L2 acquisition be shaped by the same underlying mechanism and he demanded that the focus of L2 research should therefore be on this mechanism and on the changing knowledge of the learners (i. e. interlanguage). Acquiring grammatical properties of L2, then, is commonly understood as a sequence of "approximative" grammatical systems (within the framework of Universal Grammar, which crucially involves parameter resetting). An approximative system has some properties present in neither the L1 
nor the L2. This approximative system gradually approaches the target language. The Contrastive Analysis approach of comparing two whole languages to predict interference or transfer yields only a partial picture of L2 learning; the focus should be on the learner's own system as it develops closer towards the L2. "only by treating language learners' language as a phenomenon to be studied in its own right we can hope to develop an understanding of the processes of second language acquisition" (Corder, 1978, p.71). At each level of learners' language process in approximative system, the linguistic repertories of learners typically consist of grammars which are partially not entirely identical to the target knowledge. So, we expected by increasing the learners' level of proficiency their approximative system (especially in Advanced learners) to be resemble those of the target language.

\section{Research Questions}

1. Do Persian learners of English as L2 learners show the development of that-complement clauses systematically?

2. What are the stages through which complement clauses are acquired by Persian learners of English?

3. Do the Persian learners at any level of language acquisition produce sentences characterized "wild grammar"

\section{Research design and Methodology}

\subsection{Participants}

In this study 50 students including 15 males and 35 females were randomly selected from the 70 students of University of Guilan who their majors were English literature. Their ages were from 19 to 26. About two third of the students were on their freshman year (second semester) and others were on eighth semester. According to the results of the Oxford Proficiency Test (OPT) administrated to this sample, they were divided to three proficiency levels: Advanced, intermediate, and elementary.

\subsection{Instruments}

In the present study, a Grammatical Judgment Test (GJT) consisting of 60 items was administered to the students. The GJT was supposed to measure the properties associated with that-complement clauses in English (see the GJT in Appendix). In order to calculate the reliability of the test, we divided the tests into two parts (split half), each part of GJT consisting of 30 items nearly parallel to each other. In order to enhance the reliability of the test, the participants were instructed to select one of the choices from two alternatives as Grammatical (G) and Ungrammatical (UN). In addition, to reduce the percentage of selection by chance, they were instructed to write the correct answer if they judge a sentence as Ungrammatical (UN). The reliability of the test (Spearman Brown coefficient) was $85 \%$.

In the GJT the six variables were specified: complement in finite/nonfinite clauses (that, if, for and whether), small clauses, exceptional clauses, that-trace filter in clauses (ECP principle) and subcategorization frame (Projection principle).

\subsection{Research design}

The present study adopts a cross- sectional design to compare three groups at different proficiency levels: elementary (12 participants), intermediate (32 participants) and advanced (6 participants) with respect to the acquisition of complement clauses in English by Persian L2 learners. The advantage of this design is that we can compare our arbitrary sample at different levels in a short time.

\subsection{Procedures}

In the first step from 70 students who their majors were English literature, 50 students were randomly selected. Then, they were required to fill out a questionnaire. Next, an Oxford Proficiency Test (OPT) was administered to this sample. According to the results of the OPT, the students were divided at three proficiency levels as elementary, intermediate and advanced. Then, a GJT were administered to these three levels. In the GJT, they were required to judge whether the sentences are grammatical or ungrammatical by marking G/UN. The GJT were administered in one session for 40 minutes and the OPT in another session for 30 minutes.

\subsection{Scoring Procedures and Data Analyses}

For the GJT, each item followed by two choices as G or UN was to be judged, and if the students found out that an item was not correct, they were required to write the correct sentence in the answer sheets. They would receive one score for each correct judgment as a G or UN, but they would not gain any score for choosing the alternatives UN, when they could not find the ungrammatical points or when they select it by chance. In order to test the research hypotheses a set of statistical analyses were done to analyze the data collected by responses to GJT. In this study, two main statistical computation are performed: parametric test (i.e. ANOVA) when the variables in the samples were normally distributed whereas nonparametric test (i.e. Kruskal-Wallis Test) was done when variables were not distributed normally disputed to reveal the inter sample differences concerning the linguistic phenomena investigated in this study (complement clauses). So, the One-Sample Kolmogorov-Smirnov Test (K-S Test) procedure was used to compare the observed cumulative distribution function for each variable with the specified theoretical distribution, which may be normal, uniform, or exponential. The K-S Test was used to check the normality assumption in analysis of variance. The main goal here was to compare the students' knowledge of complement clauses at different levels of proficiency and to see 
whether the differences in the three samples are significant or not. The probability level was set at 0.05 level of significance for all tests.

\section{Results and Discussion}

We will report the results of Grammatical Judgment Test obtained from the students at the three proficiency levels through the following figures. The main goal here is to investigate the participants' knowledge of complements clauses on sixth variables in order to know how Persian learners of English as FLL acquire complement clauses.

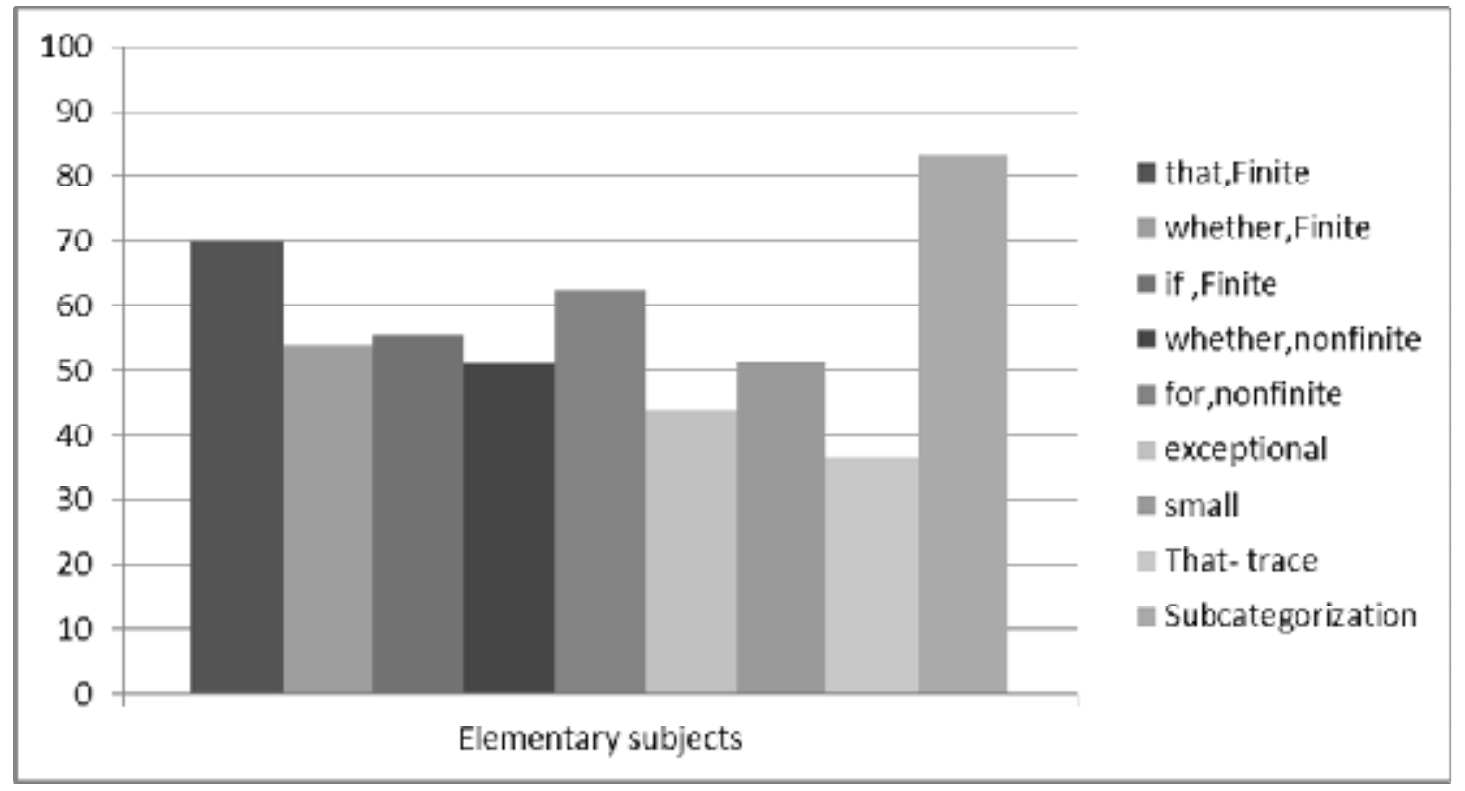

Figure 1. Elementary participants' performance on GJT

Figure 1 shows that students receive the higher scores on that clauses than whether, if and for clauses. They further obtained higher scores on whether clauses in finite than nonfinite clauses. In this group, the participants received the highest score on subcategorization variable and the lowest score on that-trace variable.

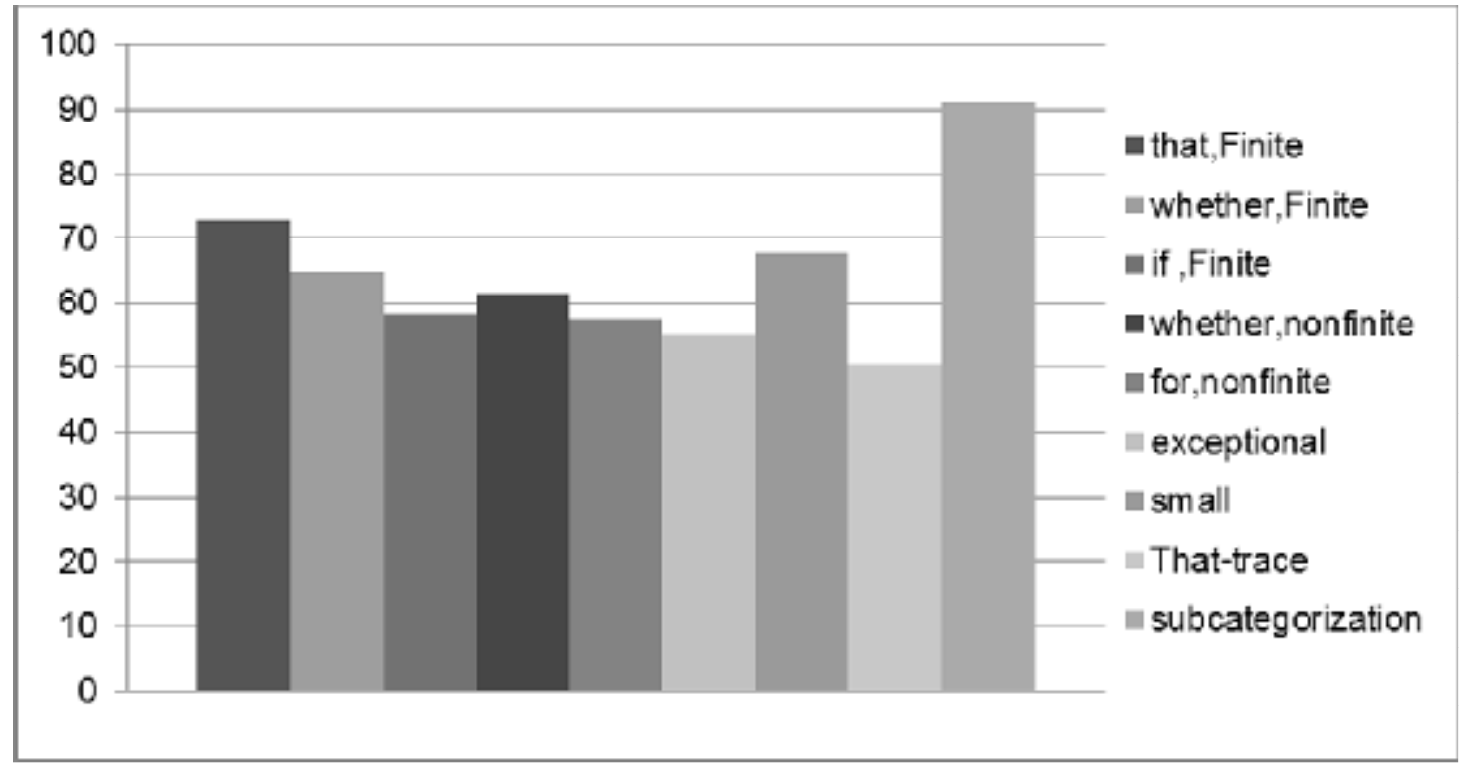

Figure 2. Intermediate subjects' performance on GJT

Figure 2 shows intermediate students' performance on finite clauses is better than nonfinite clauses and they do better on whether clauses in finite than nonfinite clauses (i. e. they gave higher score). The participants in intermediate level receive the highest scores on that-complement clauses than whether, if and for clauses. They receive the highest score on subcategorization variable and the lowest scores on that- trace filter variable. 


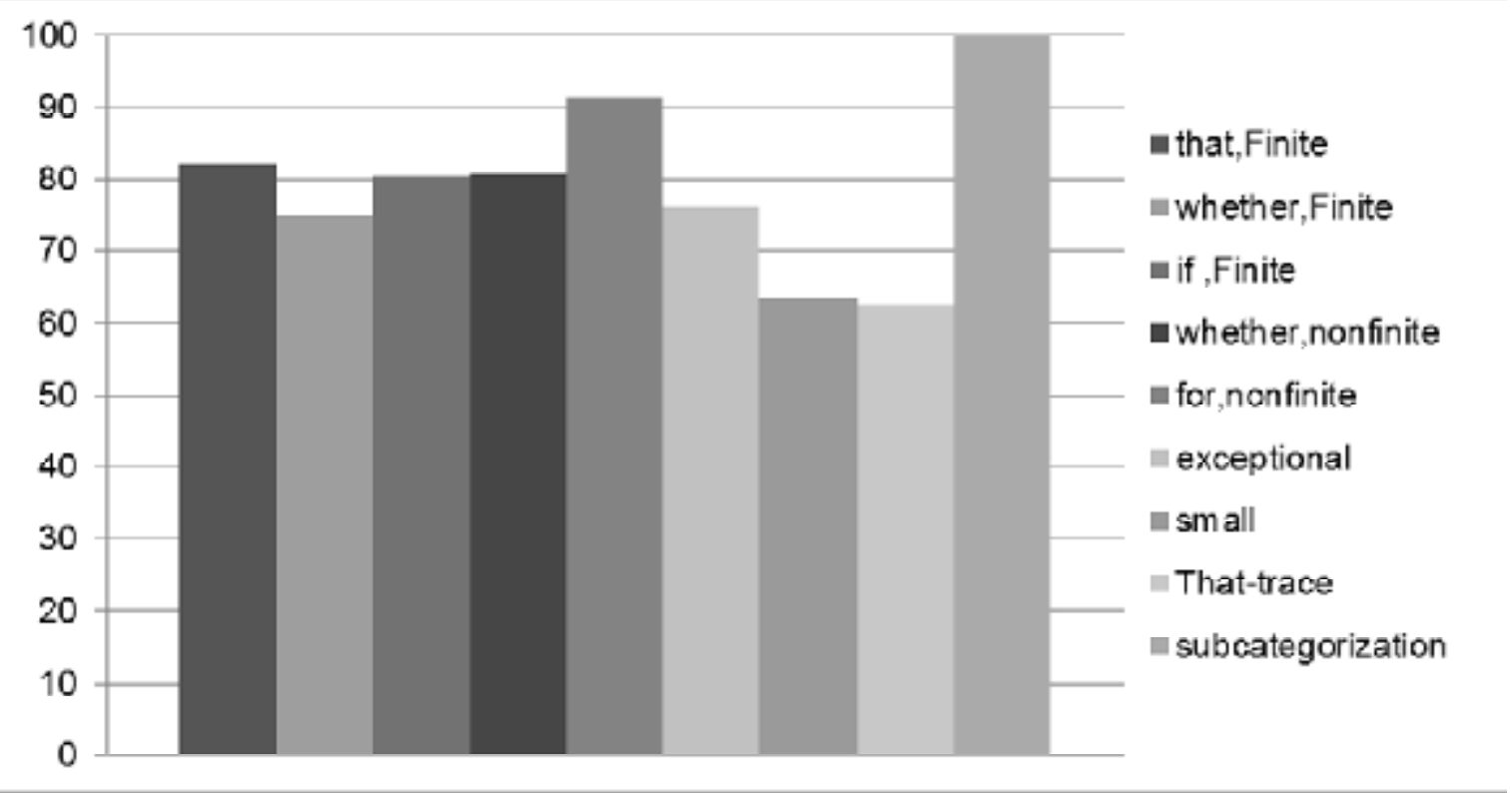

Figure 3. Advanced participants' performance on GJT

As figure 3 demonstrates all students have correctly answered to the subcategorization items in GJT (in contrast to the students at elementary and intermediate levels). In addition, they received the highest scores on that-complement in finite clauses, but they received the higher scores on whether clauses in nonfinite than in finite clauses (in contrast to elementary and intermediate subjects in this study). However, this difference is not large. They receive the highest scores on the sixth variable (subcategorization ) and the lowest scores on the fifth variable (That-trace filter) compared to the other two samples.

Table 1 shows the students' performance on GJT and compares their recognition of the grammatical and ungrammatical items at three levels of proficiency.

Table 1. comparison of students' performance on G \& Un items in GJT at 3 levels of proficiency

\begin{tabular}{ccc}
\hline Level of proficiency & Grammatical \% & Ungrammatical \% \\
\cline { 2 - 3 } Elementary & 67.87 & 48.21 \\
Intermediate & 71.03 & 60.48 \\
Advanced & 79.18 & 79.27 \\
\hline
\end{tabular}

Table 1, demonstrates that when students' level of proficiency increases, their knowledge of recognizing the grammatical and ungrammatical sentences also improves.

Table 2. Results of Students' performance on GJT at 3 levels of proficiency

\begin{tabular}{lcc}
\hline Levels of proficiency & means' scores & $\underline{\%}$ \\
Elementary & 34.33 & 57.21 \\
Intermediate & 39.25 & 65.41 \\
Advanced & 47.50 & 79.16 \\
\hline
\end{tabular}

Table 2 shows that the students' performance on GJT improves when their level of proficiency improves.

Plot 1 also shows that advanced students' mean score was higher than that of the Intermediate students' Performance and the mean scores of the Intermediate students' performance was higher than that of the elementary students' on GJT.

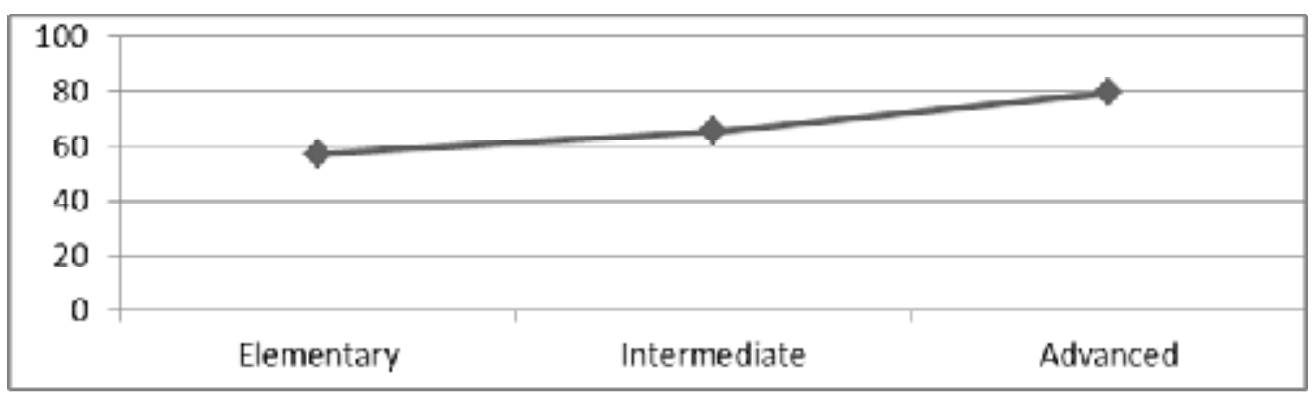

Plot 1. Comparison of three experimental samples' performance on GJT 


\section{Analyses of the results of GJT by Parametric and nonparametric tests}

To analyze the data gathered from GJT at the three levels, two main statistical computation were performed: 1) parametric test (ANOVA) was done when the variables in the samples were found to be normally distributed and followingly Post Hoc Scheffe test was done when the differences were significant to investigate which groups are different from another, and 2) nonparametric test (Kruskal-Wallis Test) was done when the variables were not normally distributed to reveal the significance of inter sample differences concerning the linguistic phenomena investigated in this study. In other words, the main goal here is to investigate whether the differences in the students' knowledge of complement clauses (i.e. their performance on GJT) at different levels of proficiency is significant or not. Therefore, a One-Sample Kolmogrove-Smirnov test was done to find out whether the distribution of the variables was normal. The results of this test showed that except the total finite and total scores, other variables are not normally distributed.

\subsection{Summary of comparison of all proficiency levels' means on all variables on GJT}

We will compare the means of three samples on all variables of GJT in this study first, and then after conducting parametric and nonparametric tests, it is also shown which variable(s) in these three samples turned out significantly to be different through table.

Table 3. Summary of comparison of all proficiency levels' means' scores on all variables on GJT

\begin{tabular}{|c|c|c|c|c|c|c|c|c|c|c|}
\hline $\begin{array}{c}\text { Level of } \\
\text { proficiency }\end{array}$ & $\begin{array}{c}\text { Finite } \\
\text { That| whether| if } \\
\text { Out of }\end{array}$ & $\begin{array}{l}\text { Total } \\
\text { Finite } \\
\text { Out of }\end{array}$ & $\begin{array}{l}\text { Nonfinite } \\
\text { Whether |for } \\
\text { Out of }\end{array}$ & $\begin{array}{c}\text { Total } \\
\text { Nonfinite } \\
\text { Out of }\end{array}$ & $\begin{array}{c}\text { Excep. } \\
\text { cl. } \\
\text { out of }\end{array}$ & $\begin{array}{l}\text { Small } \\
\text { cl. } \\
\text { out of }\end{array}$ & $\begin{array}{l}\text { That-tr. } \\
\text { Out of }\end{array}$ & $\begin{array}{c}\text { Subcategorization } \\
\text { Want } \mid \text { let } \\
\text { Out of }\end{array}$ & $\begin{array}{l}\text { Total } \\
\text { Sub. } \\
\text { Out of }\end{array}$ & $\begin{array}{l}\text { Total } \\
\text { Scores } \\
\text { Out of }\end{array}$ \\
\hline & \begin{tabular}{l|l|l}
14 & 4 & 6
\end{tabular} & 24 & 7 & 9 & 7 & 6 & 8 & 2 & 6 & 60 \\
\hline $\begin{array}{c}\text { Elementary } \\
\text { mean }\end{array}$ & $\begin{array}{c}9.83|2.16| \\
3.33 \\
\end{array}$ & 15.33 & 1.25 & 4.83 & 3.08 & 3.08 & 2.91 & \begin{tabular}{l|l}
3.16 & 1.83
\end{tabular} & 5 & 34.25 \\
\hline $\begin{array}{l}\text { Intermediate } \\
\text { mean }\end{array}$ & \begin{tabular}{|l|l|l|}
$10.21 \mid$ & 2.59 & 3.5
\end{tabular} & 16.31 & \begin{tabular}{l|l}
4.31 & 1.15
\end{tabular} & 5.46 & 3.87 & 4.06 & 4.06 & \begin{tabular}{l|l}
3.56 & 1.90
\end{tabular} & 5.46 & 39.25 \\
\hline $\begin{array}{c}\text { Advanced } \\
\text { mean }\end{array}$ & \begin{tabular}{l|l|l|}
11.5 & 3 & 4.83
\end{tabular} & 19.33 & \begin{tabular}{l|l}
5.66 & 1.83
\end{tabular} & 7.5 & 5.33 & 4.16 & 5 & 2 & 6 & 47.50 \\
\hline $\begin{array}{c}\text { Mean of } 3 \\
\text { levels }\end{array}$ & $\begin{array}{c}10.28|2.54| \\
3.62\end{array}$ & 16.44 & \begin{tabular}{l|l}
4.3 & 1.24
\end{tabular} & 5.54 & 3.86 & 3.84 & 3.90 & \begin{tabular}{l|l}
3.25 & 1.90
\end{tabular} & 5.42 & 39.04 \\
\hline $\begin{array}{l}\text { Asymp. sig. } \\
\text { K. W.T. }\end{array}$ & $0.265|0.36| 0.167$ & & $0.051 * \mid 0.119$ & $0.025^{*}$ & $0.048^{*}$ & 0.061 & $0.038^{*}$ & 0.536 & $0.055^{*}$ & \\
\hline $\begin{array}{c}\text { Sig. } \\
\text { (ANOVA) }\end{array}$ & & 0.061 & & & & & & & & $0.001 *$ \\
\hline
\end{tabular}

Notes:* Significance at $\mathrm{p}<0.05$

Table 3 shows that the performance on each variable by the participants depends on their level of proficiency. But, the performance differences of the participants at these three levels except for 'finite clauses, for in nonfinite clauses, small clauses and subcategorization(want,let) variables were significant $\left(\mathrm{p}_{-}<.05\right)$. Further, this tables shows that the three experimental samples' performance on GJT (total score) were significantly different.

6.2 Summary of comparison of all experimental levels on their performance on grammatical and ungrammatical items in GJT

Table 4. Summary of all proficiency levels' means' scores on grammatical and ungrammatical items in GJT

\begin{tabular}{|c|c|c|c|}
\hline Level of proficiency & Grammatical (27) & Ungrammatical (33) & Total sores $(60)$ \\
\hline & mean & mean & mean \\
\hline Elementary & 18.33 & 15.91 & 34.25 \\
\hline Intermediate & 19.18 & 20.06 & 39.25 \\
\hline Advanced & 21.37 & 26.16 & 47.50 \\
\hline Total means & 19.24 & 19.80 & 39.04 \\
\hline $\begin{array}{l}\text { Asymp. Sig } \\
\text { (Kruscal-Wallis Test) }\end{array}$ & 0.327 & & \\
\hline Sig. (ANOVA) & & $0.007 *$ & $0.001 *$ \\
\hline
\end{tabular}

Note: ${ }^{*}$. Significance at $\mathrm{p}<0.05$

Table 4 shows that the participants' performance (means of scores) increases parallel with the learners' level of proficiency and that the differences between three proficiency levels regarding to their performance of, ungrammatical items as well as total scores turned out to be significant $\left(\mathrm{p}_{-}<.05\right)$.

A homogenous Scheffe Test was done to find out which group is significantly different from another. The results will be presented through table 5 . 


\begin{tabular}{lccr} 
Table 5. Homogenous proficiency subset of total scores on GJT \\
\cline { 2 - 4 } Level of proficiency & $\mathrm{N}$ & \multicolumn{2}{c}{ Subset for alpha $=0.05$} \\
\hline A-elementary & 12 & 34.250 & \\
\hline B-intermediate & 32 & 39.250 & \\
\hline C-advanced & 6 & & 47.500 \\
\hline Sig. & & .250 & 1.000 \\
\hline
\end{tabular}

Scheffe ${ }^{\mathrm{a}, \mathrm{b}}$

*.Means for groups in homogeneous subsets are displayed.

a. Uses Harmonic Mean Sample Size $=10.667$.

b. The group sizes are unequal. The harmonic mean of the group sizes is used. Type I error levels are not guaranteed.

Total Sores of GJT (60)

Table 5 reveals that both elementary and intermediate levels are significantly different from advanced level on their performance on GJT. However, the elementary level and intermediate level do not show any significant difference in this regard.

To find logical answers to the research questions, it would be helpful to investigate the properties of learner's grammars at different proficiency levels to find out a relationship between the proficiency level of L2 learners and the development of complement clauses which we investigated in this study. Then, based on the finding, we may just speculate or hopefully establish an argument about how those properties developed (systematically or not) in order to answer to first question: 'Do Persian learners of English as L2 learners show the development of that-complement clauses systematically?'

As the results of data analyses of GJT of the all proficiency levels show (which the summary of which was presented in the tables1 and 2), we can see the improvement of means scores by the learners at higher levels of proficiency, on all variables investigated in this research. In addition, ANOVA and Kruskal-Wallis Tests show, the differences between groups on finite clauses in contrast to nonfinite did not turn out to be significant. In addition, the students' performance on that-clause in all experimental groups, are better than others (i.e. whether, if, for) except at advanced level in which they have received the higher scores on for-clauses. Furthermore, we can see that students' performance on Smallclause as a marked and unusual type of clause was not significantly different in the performance by the three samples, although by the increase their levels of proficiency their means' scores increased. These results can prove Cook (1997, p. 131) arguments for L2 learners stating "if L1 and L2 have the same setting, L2 learning would be similar to L1 learning. But, if the L1 and L2 setting is different, L2 learners will start from the unmarked setting which can show that L2 acquisition is the same as first language acquisition" (in contrast to what Bley-Vroman,1989 stated as FDH).

Table 2 also shows by increasing the participants' level of proficiency the participants' judgment of grammatical and ungrammatical items are improved and the differences between groups are significant too. Since the variation of participants' performance is not large, it can indicate the development of their complement clause acquisition is generally systematic. As Meisel (1998) pointed out, an important type of evidence (from developmental path in L2A) consists of linguistic variation. Although variation frequently indicates completed or incipient change, not every instance of variable language use can reasonably be interpreted as reflecting restructuring of the underlying system. So, although there are variations in the students IL, they generally show the development of complement clauses systematically.

The second question of this research was 'What are the stages through which complement clauses are acquired by Persian learners of English?' Since this research was a cross-sectional research and we gained the data from the participants which were students of English literature, at three different levels of proficiency, we can observe how Persian learners of English at these levels come to know complement clauses in different stages. Although more than $60 \%$ of participants at Elementary level and about $70 \%$ of participants at Intermediate level judged grammatical items correctly, some of them couldn't revise ungrammatical items, even though they had already judged UN sentences correctly, especially for some marked variables such as Exceptional Clauses and Small Clauses. In addition, for the grammatical items they correctly judged, it can be argued that they must have been learned through instruction, input, or by transfer of their L1 (translation), (e.g. converting nonfinite clauses to finite clauses with complementizer that). But, for Ungrammatical items which they judged correctly, it is important to figure out how they have been acquired. Since the explanation of syntax that L2 learners receive, necessarily concerns only those points that their teachers are aware of or the input they have already been exposed to (i.e. positive evidence), it is crucial to find out how people (FLL) know what they are not taught or exposed to or which doesn't exist in their L1 (i.e. negative evidence).

Negative evidence in second language interaction might take two forms: 1) correction offered by a teacher; 2) rephrasing of a learner's second language utterance offered by a native-speaking conversational partner. Since "the correction often seems ineffective" (Mitchel \& Myless, 2013, p. 20), it seems that learners cannot often benefit from correction and feedback and it won't be helpful for some current theories. So, any natural language must be learnable from positive evidence rather than the negative one. In this research, we observed that in all three experimental groups, 
some participants could recognize the ungrammatical items although they had never been exposed to them (i. e. provision of no negative evidence). Furthermore, by increasing the participants' level of proficiency their realization of the ungrammatical items improved. In addition, although some of participants, who had judged the ungrammatical items ' $U N$ ' correctly, they revised them into yet other ungrammatical sentences, especially by students at elementary and intermediate levels. However, all participants at the advanced level and most of the participants at intermediate level have written correct sentences, even if they were not our target sentences. Therefore, as predicted the students at Elementary and Intermediate level could learn the structures later by increasing their level of proficiency (i.e. at upper levels). In other words, the judgment of the grammatical and ungrammatical sentences could improve as their level of proficiency increases. Thus, we can conclude that language process of Elementary and Intermediate level of proficiency seems to be in line with an approximative system and those at the Advanced level mostly in parameter resetting.

A syntactic analysis has been done in order to answer to our third research question. Table 6 presents the percentage of the students who know, almost know or don't know the variables' structures investigated in this study which are interpreted based on the sentences that students have written in the answer sheet instead of the grammatical and ungrammatical items.

Table 6. The summary of syntactic Analyses of all proficiency levels' performance on GJT

\begin{tabular}{|c|c|c|c|c|c|c|c|c|c|c|}
\hline $\begin{array}{l}\text { Level } \\
\text { proficiency }\end{array}$ & of & that & whether & if & for & $\begin{array}{l}\text { That } \\
\text { whether }\end{array}$ & $\begin{array}{l}\text { Exceptional } \\
\text { Cl. G Items }\end{array}$ & $\begin{array}{l}\text { Small Cl. } \\
\text { G Items }\end{array}$ & $\begin{array}{l}\text { That-trace } \\
\text { G items }\end{array}$ & $\begin{array}{l}\text { Subcategorization } \\
\text { Want } \backslash \text { let }\end{array}$ \\
\hline Elementary & $\begin{array}{l}+ \\
+- \\
-\end{array}$ & $\begin{array}{l}66 \% \\
44 \%\end{array}$ & $\begin{array}{l}16.6 \% \\
75 \% \\
8.33 \%\end{array}$ & $\begin{array}{l}41.67 \% \\
33.37 \% \\
25 \%\end{array}$ & $\begin{array}{l}41.67 \% \\
33.37 \% \\
25 \%\end{array}$ & $\begin{array}{l}33.73 \% \\
66.67 \%\end{array}$ & $\begin{array}{l}12: 16.66 \% \\
26: 50 \% \\
58: 50 \%\end{array}$ & $\begin{array}{l}20: 33 \% \\
46: 8.33 \% \\
49: 66 \%\end{array}$ & $\begin{array}{l}17: 4066 \% \\
48: 75 \% \\
59: 83 \%\end{array}$ & $\begin{array}{l}50 \%+ \\
50 \%+-\end{array}$ \\
\hline Intermediate & $\begin{array}{l}+ \\
+- \\
+\end{array}$ & $\begin{array}{l}71.87 \% \\
28.12 \% \\
0\end{array}$ & $\begin{array}{l}28.12 \% \\
71.87 \% \\
0\end{array}$ & $\begin{array}{l}21.87 \% \\
62.05 \% \\
15.625\end{array}$ & $\begin{array}{l}34.37 \% \\
40.62 \% \\
25 \%\end{array}$ & $\begin{array}{l}56.25 \% \\
21.87 \% \\
21.87 \%\end{array}$ & $\begin{array}{l}15.62 \%+ \\
12: 40.62 \% \\
26: 65.62 \% \\
58: 40.62 \%\end{array}$ & $\begin{array}{l}20: \\
53.12 \% \\
46: \\
18.75 \% \\
49: 75 \% \\
\end{array}$ & $\begin{array}{l}17: 50 \% \\
48: \\
17.87 \% \\
59: \\
71.87 \% \\
\end{array}$ & $\begin{array}{l}62.5 \%+ \\
37.5 \%+-\end{array}$ \\
\hline Advanced & $\begin{array}{l}+ \\
+- \\
-\end{array}$ & $100 \%$ & $\begin{array}{l}66.67 \% \\
33.37 \% \\
0\end{array}$ & $\begin{array}{l}66.67 \% \\
16.67 \% \\
16.67 \%\end{array}$ & $\begin{array}{l}83.37 \% \\
16.67 \% \\
0\end{array}$ & $100 \%$ & $\begin{array}{l}50 \%+ \\
12: 50 \% \\
26: 83 \% \\
58: 66 \%\end{array}$ & $\begin{array}{l}20: 66 \% \\
46: 0 \\
49: 50 \%\end{array}$ & $\begin{array}{l}17: 50 \% \\
48: 66 \% \\
59: 83 \%\end{array}$ & $100 \%+$ \\
\hline
\end{tabular}

Notes: + : students know the structure

+- : students almost know the structure

-: students do not know the structure

Columns 7, 8, and 9 represent the numbers of grammatical items in GJT related to these variables \& the percentage of participants who judged them Correctly.

As table 6 shows, almost for all variables the participants' performance improves in parallel to the increase in their level of proficiency, and this improvement on some variables such as that-complement, that-whether clauses and exceptional clauses seems to be greater than the others. But in some variables such as small clauses the differences is not large. As we mentioned earlier, the differences between the performances of the learners at the three levels of proficiency on small clause variable were not significant. It can thus be concluded that some formal (or marked) structures such as small clauses seems to be more problematic than others in second language acquisition.

For third question: 'do the Persian learners at any level of language acquisition show any indication of any wild grammar development?' we had syntactic analysis of sentences which participants in this research produced as alternatives for grammatical and ungrammatical items in GJT. Now, we deal with the likely reasons why they produced such sentences.

According to Chomsky (2000, p. 4), "evidently each language is the results of the interplay of two factors: the initial state and the course of experience". We can think of initial state as a 'language acquisition device' that take experience as 'input' and gives the language as an 'output' that is internally represented in the mind/ brain. Learners' performance in a second language is obviously influenced by the language or languages that they already know. This phenomenon is called transfer. Although behaviorists view language transfer as an important source of error and interface with SLL, from a Universal Grammar perspective the language transfer problem is looked at somewhat differently. If second language learners always have direct access to their underlying UG, first language influence will affect only more peripheral areas of second language development. If on the other hand, learners only access to UG is indirect, via the working example of natural language that the first language provides, then, first language influence lies at the heart of SLL. Therefore, Exceptional and Small clause structure could be as a peripheral structure rather than core grammar that is the first language of participants must have influenced their judgment of the items. In the case of That-trace filter most students at Elementary and intermediate level judged items based on their L1. Thus, they judged items 15, 18, 29, 45 and 47 which were ungrammatical, incorrectly, as grammatical.

By looking at the participants' performance in GJT (on grammatical and ungrammatical items) we can conclude that whenever they failed to correct the ungrammatical items, it was because of L1 transfer or overgeneralization, but not 
because of violating of the universal principles. In other words, Persian learners do not seem to produce any sentence with wild grammar at any level of their language acquisition.

\section{Conclusions}

Since in Persian there is only one complementizer ' $K e$ ' (equivalent to 'that' complementizer in English) which have different meaning and use in contrast to English language, in this study we have investigated how Persian learners of English as second language learners, at different levels of proficiency acquire such structures. In order to evaluate the participants' acquisition of complement clauses and find out appropriate answers to our research questions, we have analyzed the data through two main statistical computations: parametric and nonparametric tests. Our findings are as follows:

The participants' performance on all variables investigated in this study, by increasing the students' level of proficiency was improved. Furthermore, the differences between groups, on all variables except on finite clauses, for in nonfinite clauses, small clauses and subcategorization (want, let) were significant. In addition, by increasing the participants level of proficiency the participants' judgment of grammatical and ungrammatical items were improved. Since the differences between groups were significant and the variation of participants' performance was also not large and students' L1 had important role on their L2 acquisition, it can indicate that the development of complement clauses are generally systematic and the participants' performance is not due to the indeterminate intuition as Bley-Vroman FDH (1989) stated. In addition, language process of Elementary and Intermediate level of proficiency seems to be in line with an approximative system and those at the Advanced level mostly in parameter resetting. So, elementary, intermediate and advanced students were on second, third and fourth stages respectively. By looking at the participants performance on GJT (on grammatical and ungrammatical items), we can conclude that whenever they produced sentences for ungrammatical items, which were not grammatically correct, it was because of their L1 transfer or overgeneralization or etc., but not violating any of the universal principles. In other words, Persian learners as UG predicted, do not seem to produce any sentences with wild grammar at any level of their language acquisition. Therefore, it is important that L2 learners in second language acquisition be taught these structures investigated in this research inductively or deductively. L2 teachers should also gain insights to be more tolerant about their students' developmental approximation toward the target system.

\section{References}

Bley-Vroman, R. (1989). What is the logical problem of foreign language learning? In L. Eubank, (1991). Point counterpoint universal Grammar in the second language. John Benjamins.

Bley-Vroman , R. (1990). The logical problem of foreign language learning. Linguistic Analysis, 20, 3- 49.

Bley-Vroman, R. (2009). The evolving context of the fundamental difference hypothesis. Studies in Second LanguageAcquisition, 31, 175-198.

Clahsen, H. \& Hong, U. (1995). Agreement and null subject in German L2 development: new evidence from reaction - time experiment. Second Language Research 11,(1), 57-58.

Chomsky, N. (1986a). Knowledge of language. New York: Praeger. In R .Hawkins (2001). Second language syntax. Blackwell.

Chomsky, N. (1992). A Minimalist program for linguistic theory. MIT Occasional Working Papers in Linguistics, 1. (Also appeared in K. Hale \& S. Keyser (Eds.) (1993), The view from building 20 (pp. 1-52). Cambridge, MA: MIT Press.

Chomsky, N. (2000). New horizons in the study of language and mind. Cambridge, UK ; New York: Cambridge University Press.

Clahsen, H. and Muysken, P. (1986). The availability of Universal Grammar to adult and child learners: a case study of the acquisition of German word order. Second Language Research. 2, 2: 93-119. In M. Al-Hamed,(1998). Why

might some researchers believe that the same components of mind which facilitate L1 acquisition (Universal Grammar) also underlie L2 acquisition?

Clahsen, H., \& Felser, C. (2006). Grammatical processing in language learners. Applied Psycholinguistics, 27, 3-42.

Cook, V. J. (1993). Linguistics and Second Language Acquisiti Macmillan. BasinToke: Macmillan.

Cook, V. J. (1997) Chomsky's Universal grammar and second language acquisition. Blackwell.

Diessel, H. \& Tomasello, M. (2001). The acquisition of finite complement clauses in English: a corpus based analysis.

Cognitive Linguistic, 12,97-141.

Dulay, H., \& Burt, M. 1977. Remarks on creativity in language acquisition In M. Burt, H. Dulay , \& M. Finocchiaro (eds.): Viewpoints on English as a second language. New York: Regents, pp. 95-126.

Dulay, H., Burt, M. and Krashen, S. (1982). Language two. New York: Oxford University Press.

Ellis, R. (2003). Second language acquisition. Oxford University Press. 
Epstein, S. D., Flynn, S. \& Martohardjono, G. (1996). Second language acquisition: theoretical and experimental issues in contemporary research. Brain and Behavioral Sciences, 19, 677-758. In L. White, (1998). Universal grammar in second language acquisition: The nature of inter-language representation. Blackwell.

Eubank, L. (1991). Point counterpoint Universal Grammar in the second language. John Benjamin.

Flynn, S. (1996). A parameter-setting approach to second language acquisition. In R. Mitchell \& F. Myles, (1998). Second language learning Theories. Arnold.

Johnson, J. \& Newport, E. (1989). Critical period effects in second language learning: the influence of maturational state on the acquisition of English as a second language. Cognitive Psychology, 21, 60-99. In D. D. Steinberg, (2006) pp: 123-137. An Introduction to Psycholinguistics 2ed, Pearson Logman.

Kidd, E. Lieven, E. \& Tomasello, M. (n.d), The acquisition of complement clauses constructions: A sentence repetition study.

Lenneberg, E. (1967). Biological foundations of language. New York: Wiley. In B. Kumaravadivelu, (2006). Understanding Language Teaching from Method to Post method. Lawrnec Erlbaum Associates.

Maclaughlin, B. (1987). Theories of Second Language Learning. London: Edward Arnold . In M.H. Keshvarz, (2012). Contrastive analysis and error analysis. Rahnama Press.

Meisel, J. M. (2011). First and second language acquisition: parallels and differences. Cambridge University Press.

Mitchell, R. \& Myles, F. (1998). Second language learning theories. Arnold.

Mitchell, R. \& Myles, F.\& Marsden, M.( 2013). Second language theories. Routledge.

Otsu, Y. \& Naoi, K. (1986). Structure-dependence in L2 Acquisition in L. White, (1989). Universal Grammar and Second Language Acquisition. John Benjamins. B.V.

Radford, A. (1997). Transformational Grammar a first course. Cambridge University Press.

Radford, A. (1998). Syntactic theory and the structure of English: a minimalist approach. Cambridge: Cambridge University Press.

Robinson, P. (2002). Individual differences and instructed language learning. John Benjamins. B. V.

Sanchez Perez, L. (2010). Sytematicity and variability in overtime IL development:Developmental sequences in the acquisition of order within VPS in English as a foreign language. 59-83

Schachter, J. (1989). Testing a proposed universal. In V. Cook, (1993). Linguistics and second language acquisition. Macmillan.

Selinker, L. (1969). Language transfer. General Linguistics, 9, 67-92. In R.Mitchell, F. Myles, \& M. Marsden, ( 2013). (pp. 1-13). Second language theories. Routledge.

Selinker, L. (1972). Interlanguage. IRAL, 10, 209-231. In R. Mitchell, F. Myles, \& M. Marsden, 2013. (pp. 1-13). Second language theories. Routledge.

Sharwood Smith, M. (2004). In two minds about grammar: On the interaction of linguistics and metalinguistic knowledge in performance. Transactions of the Philological Society 102, (2), 225-280.

Sharwood Smith, M., and Truscott, J. (2005). Stages or Continua in Second Language Acquisition: A MOGUL Solution. Applied Linguistics 26, (2), 219-240.

Thompson, S. A., \& Mulac, A. (1991). A quantitative perspective on the grammaticalization of epistemic parentheticals in English. In E. Kidd, Lieven, E. \& M. Tomasello, (n.d). The acquisition of complement clauses constructions: A sentence repetition study.

Towell, R. \& Howkins, R. (1994). Approaches to second language acquisition. Bristol: Longman Press.

Truscott, J. and Sharwood Smith, M. (2004). Acquisition by processing: A modular approach to language development.

Bilingualism: Language and Cognition 7, (1), 1-20.

White, L. (1985). Is there a logical problem of second language acquisition? TESL Canada 2,(2), 29- 41. In L. Whit (1998). Universal grammar in second language acquisition: The nature of interlanguage presentation.

White, L. (1989). Universal Grammar and Second Language Acquisition. John Benjamins. B.

White, L. (1992). Long and short verb movement in Second Language Acquisition. Canadian Journal of linguistics 37, 273- 286.

White, L. (1998). Universal Grammar in Second Language Acquisition: The nature of Interlanguage Representation. Presented at GASLA.

White, L. (2003). Second language acquisition and universal grammar. Cambridge: Cambridge University Press. 
1. I don't know whether I should agree.

2. I don't know if to agree.

3. The committee may insist that he should resign.

4. Mary might think that he will resign.

5. I am anxious that you should arrive on time.

6. I don't know if I should agree.

7. I don't know that whether to agree.

8. They are anxious for you make up your mind.

9. Mary thinks that Betty is happy.

10. I will ask that whether to come to the party.

11. I want you to become a doctor.

12. I believe the president to be right.

13. The president is not sure that to be a candidate.

14. I protested to the police I was innocent.

15. Who do you think that will telephone?

16. I believe that the president incapable of deception.

17. Who do you think that Bill will phone?

18. Whom do you think that will arrive first?

19. I consider that John extremely intelligent.

20. Could you let the cat in to the house?

21. I let him go.

22. I expect that Mary to pass the test.

23. Betty wonders that whether Mary accepted the offer.

24. I believe that Bill left.

25. I don't know if I should see a doctor.

26. I consider my student to be conscientious (careful to do their job).

27. I think that Mary will win the prize.

28. They reported that the patient to be in great pain.

29. Who do you think that will go?

30. I want that Bill leaves.

31. I don't know that whether I should go.

32. I don't know if to buy a car.

33. The teacher may insist that he should pass the exam.

34. I believe that he is a nice man.

35. I am anxious that you to arrive on time.

36. I will ask if to come to the party.

37. I am not sure that whether to give him this one.

38. They are anxious for you to make up your mind.

39. I know that you are tired.

40. I don't know that whether to write the letter.

41. I don't want that Linda to hear about this.

42. I believe for the doctor to be right.

43. Nobody will tell you that to work harder.

44. Mike grunted he was tired.

45. Who do you think that will invite?

46. I believe the victim incapable of deception.

47. Who do you think that will arrive later?

48. Whom do you think that John will invite?

49. He may consider Mary utterly (completely) incompetent.

50 . Why not let that everyone go home?

51. The policeman let him describe the accident.

52. I don't expect that you to win.

53. They will wonder that whether John will win the match.

54. The policeman believes that the victim knew his killer.

55 . I will ask if to buy the book.

56. I've never known that the Prime minister to Lie.

57. I don't know that to believe him.

58. They reported the president to be in danger.

59. Who do you think had sent the flowers?

60. I want this letter typed today. 